"This is the peer reviewed version of the following article: [The Medical journal of Australia, 2020, 213, (7), pp. 327-328] which has been published in final form at [https://onlinelibrary.wiley.com/doi/10.5694/mja2.50756] purposes in accordance with Wiley Terms and Conditions for Self-Archiving." 


\title{
Implementing cardiovasculardisease preventive care guidelines in general practice: an opportunity missed
}

\author{
Charlotte M Hespe ${ }^{1}$, Anna Campain ${ }^{2,3}$, Ruth Webster ${ }^{2}$ (D) , Anushka Patel ${ }^{2}$, Lucie Rychetnik ${ }^{1,4}$, Mark F Harris ${ }^{5,6}$, David P Peiris ${ }^{6}$ (D)
}

C ardiovascular disease (CVD) is the leading cause of death in Australia. ${ }^{1}$ New treatment guidelines based on absolute CVD risk estimates were adopted in $2012 .{ }^{2}$ General practitioners are central to implementing these guidelines, as about $90 \%$ of people in Australia consult GPs each year, ${ }^{3}$ but large evidence-practice gaps in the management of people with CVD in general practice have been reported. ${ }^{4}$

We therefore examined implementation of the 2012 CVD guidelines in general practice by analysing baseline electronic medical record (eMR) data from two clinical trials of computer-supported interventions for improving CVD care conducted during 20152018, the INTEGRATE ${ }^{5}$ and Q Pulse studies. ${ }^{6}$ Our analysis is based on data for 102225 patients from 95 general practices in four Australian states and territories. The study was approved by the Human Research Ethics Committees of the University of Sydney (reference, 2015/616) and the University of Notre Dame (reference, 014105S/016011S).

De-identified eMR data - demographic information, medical history, prescribed medications, smoking status, blood pressure, low-density lipoprotein cholesterol (LDL-C) levels - were extracted at each practice with the CAT 4 Clinical Audit tool (PenCS). Absolute CVD risk was calculated according to current guidelines ${ }^{2}$ and patients with a documented CVD diagnosis (coronary heart disease, cerebrovascular disease, peripheral vascular disease, left ventricular hypertrophy, atrial fibrillation, or heart failure) were identified (Box 1).

Guideline-recommended treatment was defined as the prescribing of blood pressure- and lipid-lowering medications for patients at high CVD risk, and also of antiplatelet or anticoagulant medications for patients with established CVD (Supporting Information). The proportions of patients who had attained treatment targets for blood pressure $(<140 / 90 \mathrm{mmHg}$ for patients at high CVD risk, $<130 / 80 \mathrm{mmHg}$ for people with established CVD or diabetes) and LDL-C level $(<2.0 \mathrm{mmol} / \mathrm{L})$ were calculated.

Of 102225 patients in the two studies, 10631 (10.4\%) had established CVD and 12983 (12.7\%) clinically high risk conditions; estimated CVD risk was high for 2760 (2.7\%) and low or intermediate for 46205 people (45.2\%), while the available eMR data were inadequate for estimating risk for 29645 participants (29\%).

1 Flow chart of patient risk and treatment identification

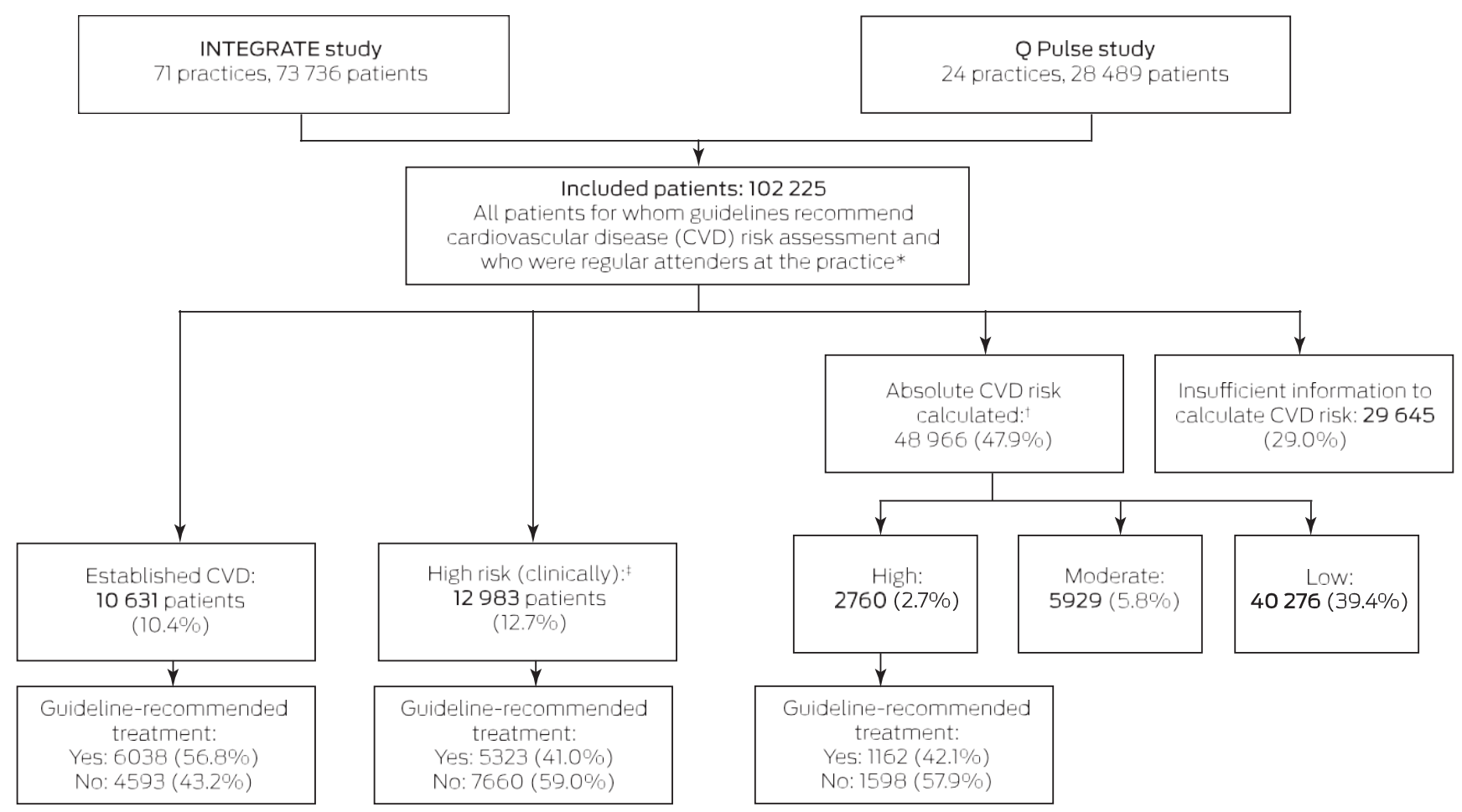

* Including Aboriginal and Torres Strait Islander people aged 35 years or more and non-Indigenous Australians aged 45 years or more, and people of any age at clinically high risk of CVD.

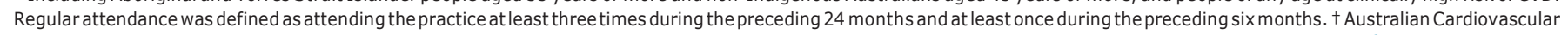

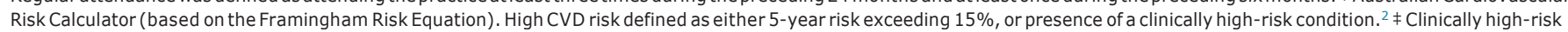

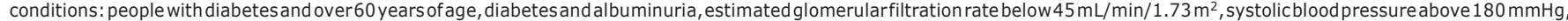
diastolicblood pressureabove $110 \mathrm{mmHg}$, ortotalcholesterollevelexceeding $7.5 \mathrm{mmol} / \mathrm{L}$.

\footnotetext{
${ }^{1}$ The University of Notre Dame Australia, Sydney, NSW. ${ }^{2}$ The George Institute for Global Health, Sydney, NSW. ${ }^{3}$ University of New South Wales, Sydney, NSW. ${ }^{4}$ The Australian Health

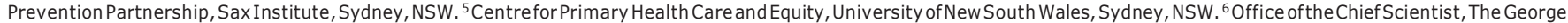
Institute for Global Health, Sydney, NSW. $₫$ charlotte.hespe@nd.edu.au • doi: 10.5694/mja2.50756
} 


\section{Prescribing practices and attainment of blood pressure and lipid targets for patients with established cardiovascular} disease or at high risk of cardiovascular disease

\begin{tabular}{|c|c|c|}
\hline & $\begin{array}{l}\text { Established } \\
\text { cardiovascular } \\
\text { disease }\end{array}$ & $\begin{array}{l}\text { High } \\
\text { cardiovascular } \\
\text { disease risk }\end{array}$ \\
\hline Number of patients & 10631 & 15742 \\
\hline \multicolumn{3}{|l|}{ Medications prescribed } \\
\hline $\begin{array}{l}\text { No risk-lowering } \\
\text { medications }\end{array}$ & $2137(20.1 \%)$ & $3731(23.7 \%)$ \\
\hline $\begin{array}{l}\text { Blood pressure-lowering } \\
\text { medication only }\end{array}$ & $1340(12.6 \%)$ & $3542(22.5 \%)$ \\
\hline $\begin{array}{l}\text { Lipid-lowering medication } \\
\text { (statin) only }\end{array}$ & $1116(10.5 \%)$ & $1983(12.6 \%)$ \\
\hline All guideline treatments* & $6038(56.8 \%)$ & $6486(41.2 \%)$ \\
\hline \multicolumn{3}{|l|}{ Clinical targets achieved } \\
\hline Blood pressure $^{+}$ & $4114(38.7 \%)$ & $8988(57.1 \%)$ \\
\hline $\begin{array}{l}\text { Low-density lipoprotein } \\
\text { cholesterol }^{\ddagger}\end{array}$ & $5645(53.1 \%)$ & $5714(36.3 \%)$ \\
\hline \multicolumn{3}{|c|}{$\begin{array}{l}\text { * Oneormoreblood pressure-loweringmedicationsandastatin; forpeoplewithestab- } \\
\text { lished cardiovascular disease, either an antiplatelet or anticoagulant medication is also rec- } \\
\text { ommended (Supporting Information). + High cardiovascular disease risk: }<140 / 90 \mathrm{mmHg} \text {; } \\
\text { establishedcardiovasculardiseaseordiabetes: }<130 / 80 \mathrm{mmHg} \text {. }<<2 \mathrm{mmol} / \mathrm{L} \text {. }\end{array}$} \\
\hline
\end{tabular}

Among patients with established CVD, 6038 (56.8\%) had been prescribed the guideline-recommended treatments; blood pressure targets had been achieved by 4114 patients $(38.7 \%)$ and LDL targets by 5645 (53.1\%). Among the 15743 patients at high CVD risk, $6486(41.2 \%)$ were prescribed recommended treatments;
$8988(57.1 \%)$ had achieved blood pressure targets and 5714 (36.3\%) LDL-C targets (Box 1, Box 2).

Our findings indicate that primary care management of patients with CVD is sub-optimal. Adopting the absolute risk assessment approach has not improved adherence to management guidelines ${ }^{4,7}$ similar to the experience in Europe, Canada, and the United Kingdom. ${ }^{8,9}$

We may have underestimated CVD risk for patients already receiving blood pressure- and lipid-lowering therapies. Risk estimates were based on information in eMR structured data fields; additional information recorded as free text was not considered. Rural and Aboriginal Medical Service practices were underrepresented in our practice sample.

GPs play essential roles in identifying patients at risk of CVD and managing their treatment, ${ }^{10}$ but ensuring their adherence to evidence-based recommendations is challenging. While risk assessment tools are important, overcoming patient, GP, and health system barriers to changes in care delivery will be critical to progress.

Acknowledgements: The University of Notre Dame received a Bupa Health Foundation grant for research into cardiovascular disease and diabetes that funded the Q Pulse study and a quality improvement project in 46 practices in the Central and Eastern Sydney Primary Health Network. Ruth Webster is supported by a National Health and Medical Research Council (NHMRC) Early Career Fellowship (APP1125044), Anushka Patel by an NHMRCPrincipal Research Fellowship (APP1136898), and David Peiris by a Heart Foundation Future Leader Fellowship (101890) and NHMRC Career Development Fellowship (APP1143904).

Competing interests: George Health Enterprises, the social enterprise arm of the George Institute for Global Health, has received funding for the development of fixed dose combination therapy, and has commercial relationships involving digital innovations similar to the interventions in the INTEGRATE study.

Received 21 September 2019, accepted 29 May 2020

(c) 2020 AMPCo Pty Ltd
1 Australian Institute of Health and Welfare. Deaths in Australia. Updated 6 Aug 2020. https://www.aihw.gov.au/reports/life-expec tancy-death/deaths-in-australia/contents/leadi ng-causes-of-death (viewed Aug 2020).

2 National Vascular Disease Prevention Alliance. Guidelines for the management of absolute cardiovascular disease risk. Apr 2012. http:// www.cvdcheck.org.au/pdf/Absolute_CVD_ Risk_Full_Guidelines.pdf (viewed May 2020).

3 Royal Australian College of General Practitioners. General practice: health of the nation 2018. Sept 2018. https://www.racgp.org. au/download/Documents/Publications/Healthof-the-Nation-2018-Report.pdf (viewed Aug 2020).

4 Webster RJ, Heeley EL, Peiris DP, et al. Gaps in cardiovascular disease risk management in Australian general practice. Med J Aust 2009;
191: 324-329. https://www.mja.com.au/journ al/2009/191/6/gaps-cardiovascular-disease-riskmanagement-australian-general-practice.

5 Joshi R, Patel A, Peiris D, et al. INTegrated Electronic General practice support tool, phaRmacy led intervention And combination Therapy Evaluation trial (INTEGRATE) [abstract]. HeartLung Circ 2015;24(Suppl3): S385.

6 Hespe $\mathrm{CH}$. Q Pulse. Reducing cardiovascular disease (CVD): translating an evidence based quality improvement tool into "real-world" general practice [ANZCTR registration: ACTRN 12615000108516]. Updated Jan 2018. https:// www.anzctr.org.au/Trial/Registration/Trial Review. aspx?id=367376\&isReview=true (viewed May 2020).

7 Heeley EL, Peiris DP, Patel AA, et al. Cardiovascular risk perception and evidence-practice gaps in Australian general practice (the AusHEART study). Med J Aust 2010; 192: 254-259. https://www.mja.com.au/ journal/2010/192/5/cardiovascular-risk-perce ption-and-evidence-practice-gaps-austr alian-general.

8 NieuwlaatRSJ, Khatib R, YusufS. Why are we failing to implement effective therapies in cardiovascular disease? Eur Heart J 2013; 34: 1262.

9 Sheppard JP, Fletcher K, McManus RJ, Mant J. Missed opportunities in prevention of cardiovasculardisease in primary care: a crosssectional study. BrJ Gen Prac2014; 64: e38-e46.

10 Berwick DM. Lessons from developing nations on improving health care. BMJ2004; 328 :

1124-1129.

\section{Supporting Information}

Additional Supporting Information is included with the online version of this article. 